\title{
A New Thalamic Pathway of Vibrissal Information Modulated by the Motor Cortex
}

\author{
Nadia Urbain and Martin Deschênes \\ Centre de Recherche, Université Laval Robert-Giffard, Québec City, Québec, Canada G1J 2G3
}

\begin{abstract}
Three ascending pathways of information processing have been identified so far in the vibrissal system of rodents. In the ventral posterior medial nucleus of the thalamus, two of these pathways convey information through the core and tail of barrel-associated structures, called barreloids. The other pathway transits through the posterior group nucleus. The present study provides anatomical and electrophysiological evidence for the existence of an additional pathway that passes through the head of the barreloids. This pathway arises from multiwhisker-responsive cells in the principal trigeminal nucleus and differs from the classic lemniscal pathway, in that constituent thalamic cells have multiwhisker receptive field and receive corticothalamic input from lamina 6 of the vibrissa motor cortex. It is suggested that this pathway might be involved in relaying signals encoding phase of whisker motion during free whisking.
\end{abstract}

Key words: vibrissa; barrels; barreloids; parallel pathways; trigeminothalamic; whisking

\section{Introduction}

The somatic sensory system of rodents is characterized by a prominent representation of the mystacial vibrissas. On each side of the rat's snout, there are five horizontal rows of vibrissas that form an orderly array of low-threshold mechanoreceptors. Each peripheral fiber innervating these mechanoreceptors responds to only one vibrissa, and centrally, the arrangement of the vibrissal pad is maintained in arrays of cellular aggregates referred to as barrelettes (brainstem), barreloids (thalamus), and barrels (cortex).

In the ventral posterior medial nucleus (VPM) of the thalamus, barreloids form curved, obliquely oriented tapering rods that extend from the border of posterior group nucleus (Po) to the ventral lateral part of the VPM (VPMvl) (Land et al., 1995; Haidarliu and Ahissar, 2001; Varga et al., 2002). Previous studies have shown that individual barreloids are composed of core and tail compartments, which receive vibrissal input from the principal trigeminal nucleus $(\mathrm{PrV})$ and the caudal segment of the trigeminal interpolar nucleus (SpVic), respectively (Pierret et al., 2000; Veinante et al., 2000). In addition, several anatomical studies have pointed out to a functional specialization of the dorsalmost part of the barreloids that abuts Po (hereinafter referred to as the head of the barreloids). This region receives input from specific sets of PrV, reticular thalamic, and corticothalamic fibers (Bourassa et al., 1995; Deschênes et al., 1998; Veinante and Deschênes, 1999; Désîlets-Roy et al., 2002), and it was also proposed that cells in the head of the barreloids might receive corticothalamic input from the motor cortex (Deschênes et al., 1998). Yet, no physiological study has reported distinct response properties

\footnotetext{
Received June 27, 2007; revised Aug. 10, 2007; accepted Sept. 17, 2007.

This work was supported by Canadian Institutes of Health Research Grant MT-5877 (M.D.).

Correspondence should be addressed to Dr. Martin Deschênes, (entre de Recherche, Université Laval RobertGiffard, 2601 de la Canardière, Québec City, Québec, Canada G1J 2G3. E-mail: martin.deschenes@crulrg.ulaval.ca. D0I:10.1523/JNEUROSCI.2914-07.2007

Copyright $\odot 2007$ Society for Neuroscience $\quad 0270-6474 / 07 / 2712407-06 \$ 15.00 / 0$
}

for cells located in the head of the barreloids. Here we show that the head region differs from the rest of the barreloid, in that residing cells exhibit multiwhisker receptive field and receive corticothalamic input from lamina 6 of the vibrissa motor cortex. Together with the aforementioned anatomical data, these results support the notion that the head, core, and tail of the barreloids serve as relay stations for three parallel pathways of vibrissa information processing.

\section{Materials and Methods}

The present experiments were conducted in accordance with federally prescribed animal care and use guidelines. The University Committee for Animal Use in Research approved all experimental protocols.

Electrophysiology. Experiments were performed in 12 male rats (250300 g; Harlan Sprague Dawley, Indianapolis, IN) under ketamine (75 $\mathrm{mg} / \mathrm{kg}$ )/xylazine $(5 \mathrm{mg} / \mathrm{kg}$ ) anesthesia. The left facial nerve was cut, and the rat was placed in a stereotaxic apparatus. The animal breathed freely, and body temperature was maintained at $37.5^{\circ} \mathrm{C}$ with a heating pad controlled thermostatically. Throughout the experiment, a deep level of anesthesia was maintained [stage III-3 (Friedberg et al., 1999)] by additional doses of anesthetics given at $1 \mathrm{~h}$ intervals $(20 \mathrm{mg} / \mathrm{kg}$ ketamine plus $0.3 \mathrm{mg} / \mathrm{kg}$ xylazine, i.m.).

Single units were recorded extracellularly in the right thalamus with micropipettes $(0.5-1 \mu \mathrm{m})$ filled with a solution of potassium acetate $(0.5$ M) and Neurobiotin (2\%; Vector Laboratories, Burlingame, CA). Signals were amplified, bandpass filtered ( $200 \mathrm{~Hz}$ to $3 \mathrm{kHz})$, and sampled at 10 $\mathrm{kHz}$. In most experiments, cell location was assessed by the juxtacellular labeling of one to three units (Pinault, 1996). At the end of the experiments, rats were perfused under deep anesthesia with saline, followed by a fixative containing $4 \%$ paraformaldehyde in phosphate buffer $(0.1 \mathrm{M}$, $\mathrm{pH}$ 7.4). Brains were postfixed for $2 \mathrm{~h}$, cryoprotected in $30 \%$ sucrose, and cut at $70 \mu \mathrm{m}$ on a freezing microtome. Sections were processed for cytochrome oxidase (CO) and Neurobiotin histochemistry according to standard protocols that were described in detail previously (Veinante et al., 2000).

Electrolytic and silver nitrate lesions. Electrolytic lesion of the interpolaris nucleus $(\mathrm{SpVi})$ and spinal trigeminal tract was performed by passing DC $(2.5 \mathrm{~mA}, 2 \mathrm{~s})$ through a tungsten electrode (shaft diameter, $200 \mu \mathrm{m}$; 
tip diameter, $50 \mu \mathrm{m}$; deinsulated over $1 \mathrm{~mm}$ ). Lesions were made at frontal plane 11.5 behind the bregma [stereotaxic coordinates from the atlas of Paxinos and Watson (1986)], and current was passed at multiple depths along two descents, $400 \mu \mathrm{m}$ apart, to fully destroy the targeted region.

The barrel cortex was lesioned by the application of a small crystal of silver nitrate over the pia. This lesioning method was previously shown to produce an immediate, irreversible suppression of cortical activity (Lavallée et al., 2005). The crystal was left in place for $20 \mathrm{~min}$ to allow diffusion of the chemical to the subcortical white matter. Then, the cortical surface was abundantly rinsed with saline. Silver nitrate is a strong cauterizing agent that burns tissue; this type of lesion does not produce any bleeding or tissue swelling. After aldehyde fixation, the burnt tissue becomes brownish but turns black after CO processing. The extent of the lesion clearly showed up in the histological material as a deep black region.

Vibrissa and motor cortex stimulation. Vibrissas were cut at $10 \mathrm{~mm}$ from the skin, and we assessed the receptive field size of single units by deflecting individual vibrissas with a hand-held probe under a dissecting microscope. An audio monitor and a computer display were used to monitor the responses. In the very first experiment, however, we found that manual deflection could lead to an overestimation of receptive field size (i.e., the number of vibrissas). This is because most relay cells send dendrites into at least one adjacent barreloid (Varga et al., 2002; Lavallée and Deschênes, 2004). Thus, if a relay cell in barreloid D2 responds to manual deflection of whiskers D2 and D3, for example, responses induced by whisker D3 may actually result from the activation of relay cells in barreloid D3 that activate reticular thalamic neurons returning axons to barreloid D3, where they contact D3 neurons as well as the extrabarreloid dendrites of D2-responsive cells (Lavallée and Deschênes, 2004). Inhibition induced by reticular axons may induce a rebound burst in D2 cells, which can lead to the false conclusion that the receptive field of that cell comprises whiskers D2 and D3. Therefore, to reliably map the receptive field size of VPM cells, we used controlled whisker deflection to ensure that cells respond to the onset of the stimulus. Thus, vibrissas were individually deflected in different directions with a piezoelectric stimulator (ramp-and-hold waveforms; rise/fall times, $5 \mathrm{~ms}$; total duration, 50 $\mathrm{ms}$; amplitude, $500 \mu \mathrm{m}$; angular velocity, $1000 \%$ s; interstimulus interval, $1 \mathrm{~s}$ ) to ensure that cells responded with $\mathrm{ON}$ responses to one or several of the vibrissas that were found effective using manual deflection.

The motor cortex was stimulated with a pair of glass-insulated platinum/iridium microelectrodes (FHC, Bowdoin, ME) that was lowered at a depth of $1.6 \mathrm{~mm}$ below the pia. Stimuli consisted of single shocks (pulse duration, $200 \mu \mathrm{s}$ ) at a current intensity of 75-250 $\mu \mathrm{A}$.

Data analysis. Spike events elicited by vibrissa deflection were collected in peristimulus time histograms (PSTHs) of 20 responses with $1 \mathrm{~ms}$ bin width. Because corticothalamic synaptic potentials strongly augment during repetitive stimulation $(4-10 \mathrm{~Hz})$, the latency of evoked spikes decreases during a stimulus train. Thus, response latency was estimated as the average latency of the first spike $(n=5)$ once response amplitude had stabilized (usually after three to five shocks). Data were analyzed with the Neuroexplorer (Plexon, Dallas, TX) and Excel (Microsoft, Redmond, WA) software. Unless stated otherwise, results are reported as mean \pm SD.

Tract-tracing experiments. Two rats were used to map corticothalamic projections from the motor cortex. The vibrissa motor cortex was identified by microstimulation, and $2 \mu \mathrm{l}$ of a biotinylated dextran amine (BDA) solution (2\% BDA 10,000 in PBS; Invitrogen, Eugene, OR) was pressure injected into layer 6 (depth, $1600 \mu \mathrm{m}$ ). After a survival period of $5 \mathrm{~d}$, rats were deeply anesthetized and perfused as above. Coronal sections of the thalamus were stained for $\mathrm{CO}$, incubated with the avidinbiotinylated-horseradish peroxidase complex (Vector Laboratories) in Tris-buffered saline for $4 \mathrm{~h}$, and developed in nickel-3,3diaminobenzidine tetrahydrochloride (Ni-DAB) as a substrate.

In two rats (four injections), thalamic cells that project to the vibrissa motor cortex were retrogradely labeled with FluoroGold (2\% dissolved in $0.1 \mathrm{~m}$ cacodylate buffer, $\mathrm{pH} 7$; Fluorochrome, Denver, CO). The tracer was delivered in the deep layers of the motor area $(\sim 1600 \mu \mathrm{m})$ by passing depolarizing current pulses ( $1 \mu \mathrm{A}, 2 \mathrm{~s}$ duty cycle for $20 \mathrm{~min})$ through a micropipette (tip diameter, $30 \mu \mathrm{m}$ ). After a survival period of $2 \mathrm{~d}$, rats were perfused as above, and sections were stained for $\mathrm{CO}$ and processed for FluoroGold immunohistochemistry. After preincubation for $1 \mathrm{~h}$ in PBS with 3\% normal goat serum and $0.3 \%$ Triton X-100, sections were incubated overnight in the same mixture containing an anti-FluoroGold antiserum (1:8000; Chemicon, Temecula, CA). The antibody was revealed using a peroxidase-labeled secondary antibody (goat IgG; Chemicon) and Ni-DAB as a substrate.

Labeled neurons were reconstructed with a camera lucida using a $40 \times$ objective. Photomicrographs were taken with a Spot RT camera (Diagnostic Instruments Sterling Heights, MI) and imported in Photoshop 7.0 (Adobe Systems, San Jose, CA) for contrast and brightness adjustments.

\section{Results}

All experiments were performed in rats whose somatosensory cortical areas had been acutely lesioned by local application of silver nitrate (Fig. 1A). This ensures that the effect of motor cortex stimulation on thalamic cells was not mediated by the activation of corticothalamic cells of S1 or S2 via corticocortical connections. Lesions included the primary (S1) and second (S2) somatosensory areas, between the frontal planes 0 and 4 behind the bregma, and involved all cortical layers down to the border of the striatum. In the absence of corticothalamic input from S1 and S2, and under the relatively deep level of anesthesia used in the experiments, thalamic cells sampled in Po and VPM displayed very low spontaneous activity, consisting mostly of occasional bursts. Therefore, manual whisker deflection and motor cortex stimulation were commonly used to detect units that would otherwise be missed.

Figure $1 B$ illustrates the distribution of whisker-sensitive cells sampled in four vertical electrode penetrations $50 \mu \mathrm{m}$ apart in the VPM of a rat (see also supplemental Fig. S1, available at www. jneurosci.org as supplemental material). Starting dorsally in Po, cells were unresponsive to whisker deflection, but they strongly responded to motor cortex stimulation, exhibiting the typical facilitating response profile that characterizes lamina 6 corticothalamic input when stimuli are delivered at $>5 \mathrm{~Hz}$ (Fig. 1C) (Deschênes and Hu, 1990; McCormick and von Krosigk, 1992; Castro-Alamancos and Calcagnotto, 1999). As a rule, the first vibrissa-sensitive units encountered in dorsal VPM responded to several whiskers (Fig. 1D), and they were also driven in a facilitating manner by motor cortex stimulation (Fig. $1 E$ ). Cells with similar response properties occurred over a distance of 150-200 $\mu \mathrm{m}$. Then, they were replaced by units that responded to a single vibrissa, as commonly observed in deeply anesthetized animals. None of latter units, however, were activated from the motor cortex.

A total of 160 cells were recorded along 30 electrode tracts in five rats. Thirty-one units were located in Po, and all were activated by motor cortex stimulation at a mean latency of $10.3 \pm 3.3$ ms. Sixty-one of the 71 multiwhisker-responsive cells recorded were also driven by motor cortex (mean latency, $9.2 \pm 1.6 \mathrm{~ms}$ ), whereas none of the 85 mono-whisker-responsive cells responded to cortical stimuli. Figure $1 \mathrm{~F}$ shows the respective location of 71 multiwhisker- and 85 mono-whisker-responsive VPM cells. The depth of the units refers to the distance from the VPM/Po border as estimated by the first vibrissa-sensitive unit recorded in each vertical descent. Histograms clearly show that the vast majority of the cells with a multiwhisker receptive field were clustered in the head of the barreloids, near Po. This result was confirmed by the labeling of at least one multiwhisker unit in each experiment ( $n=8$ cells), all of which were recovered in dorsal VPM, within a distance of $<150 \mu \mathrm{m}$ from Po (Fig. 1G; see also supplemental Fig. S2, available at www.jneurosci.org as sup- 

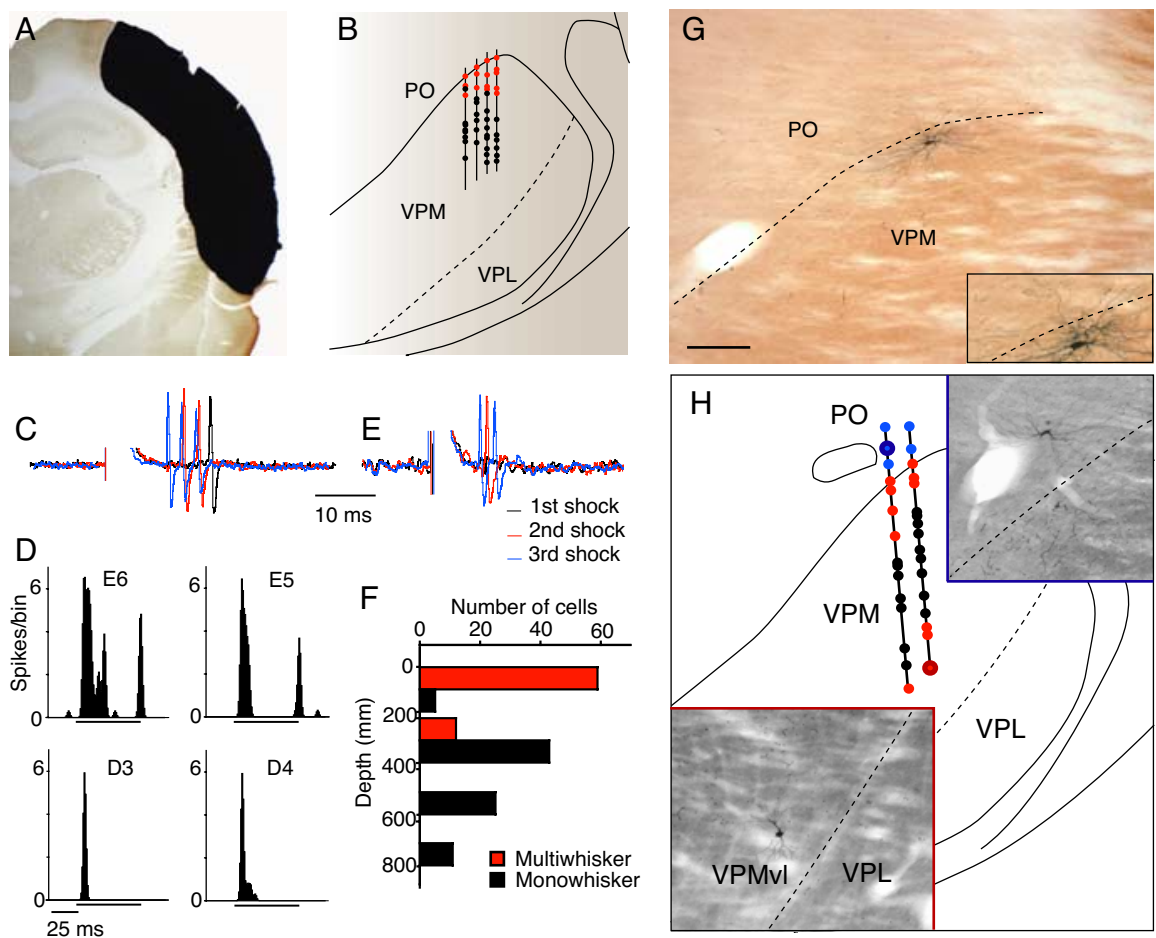

Figure 1. Electrophysiological properties of cells in the head of barreloids. $\boldsymbol{A}$, The photomicrograph shows the extent of the cortical lesion produced by application of silver nitrate on the pia. Note that the lesion involves both the first and second somatosensory areas. $\boldsymbol{B}$, The distribution of multiwhisker (red dots) and mono-whisker (black dots) units sampled along four vertical electrode tracts in a rat. $C$, Facilitating response in a Po neuron during motor cortex stimulation at $8 \mathrm{~Hz}$. Responses evoked by the first three shocks are color coded as indicated. Note that as the number of spikes increases, the latency of the first spike decreases. D, PSTHs show responses $(n=20$ ) evoked in a "head cell" by 4 of the 13 vibrissas that compose its receptive field. $\boldsymbol{E}$, Facilitating responses of the same cell during motor cortex stimulation (here, the first shock did not evoke any action potential). $\boldsymbol{F}$, The respective location of 71 multiwhisker and 85 mono-whisker cells in the VPM is summarized in the histograms. The depth of the units refers to the distance from the VPM/Po border as estimated by the first vibrissa-sensitive unit recorded in each vertical descent. Cells in the VPMvl were not sampled in these electrode tracts. $\mathbf{G}$, The photomicrograph shows the morphology and location of a representative head cell that has been labeled with Neurobiotin (scale bar, $100 \mu \mathrm{m}$ ). Note that distal dendrites extend across the VPM/Po border (inset). $\boldsymbol{H}$, When cells were sampled in Po, VPM, and VPMvl along the same descent, cells unresponsive to whisker deflection, but activated by the motor cortex, were first encountered in Po (blue dots), then followed in succession multiwhisker units that also responded to motor cortex (red dots in dorsal VPM), mono-whisker units in the core of the VPM (black dots), and finally multiwhisker units in the VPMvl (red dots). Bigger blue and red dots represent Po and VPMvl units, respectively, that were labeled with Neurobiotin (see insets). VPL, Ventral posterior lateral nucleus.

plemental material). On average, receptive fields included $6.6 \pm$ 3.3 vibrissas (range, 2-17), and receptive field topography did not exhibit any preference for row or arc of whisker representation.

In another rat, the micropipette was lowered at a mediolateral angle of $5^{\circ}$ from the vertical, to sample cells in Po, VPM, and VPMvl (i.e., the tail of the barreloids) along the same descent. Because VPMvl receives vibrissal input from SpVic neurons that respond to multiple whiskers, the expectation was to record in succession multiwhisker units in the head of the barreloids, mono-whisker units in the core of the barreloids, and again multiwhisker units in the tail of the barreloids. This is just what was observed, as shown in Figure $1 \mathrm{H}$, where electrode tract reconstructions are overlaid on a drawing of the thalamic region from which cells were recorded and labeled.

\section{Effect of brainstem lesion}

The multiwhisker receptive field of the relay cells in the head of the barreloids raises the issue of whether these cells receive input from interpolaris neurons that have large receptive field and that have terminal fields that form a shell at the margin of the VPM (Williams et al., 1994). We addressed this question by recording
VPM units in two rats in which the SpVi had been totally lesioned. The recording of 37 cells (seven electrode tracts) did not reveal any difference with the results obtained in normal rats. Units recorded in lesioned rats were pooled with those obtained in unlesioned rats in the histograms of Figure $1 F$ (see also supplemental Fig. S1, available at www.jneurosci.org as supplemental material). Histological controls confirmed that lesions completely destroyed the $\mathrm{SpVi}$ and a large part of the trigeminal tract (Fig. 2). Lesions also involved the caudal part of the oralis subnucleus, but they never extended rostrally beyond the emergence of the facial nerve. On the basis of these results, one has to conclude that the large receptive field of cells in the head of the barreloids relies on inputs from the PrV.

\section{Motor cortex input to the dorsal VPM}

At first sight, it seems odd that cells in a sensory-specific thalamic nucleus, which does not project to the motor cortex, receives corticothalamic input from the motor area. These nonreciprocal connections were, however, confirmed by tract-tracing and single-cell labeling. After FluoroGold injections into the vibrissa motor cortex (four cases), a large number of backlabeled cells were found in Po, near the dorsomedial margin of the VPM, but no retrograde labeling was observed within the VPM itself (Fig. 3A). Likewise, BDA injections in the deep layers of the motor cortex led to the anterograde labeling of a dense plexus of corticothalamic axons in Po, with some axonal branches bearing terminations that invaded the dorsal VPM (Fig. $3 B, C)$. This projection is sparse but clearly present (Fig. 3D). Also significant for the present issue is the fact that each of the VPM cells that was driven by motor cortex and labeled with Neurobiotin $(n=8)$ sent dendrites across the VPM/Po transition zone (Fig. $1 G$; see also supplemental Fig. S2, available at www.jneurosci.org as supplemental material). Thus, these observations provide an anatomical substrate for the excitatory modulation of cells in the head of the barreloids by corticothalamic axons from the motor cortex.

\section{Discussion}

Land et al. (1995) were perhaps the first to point out to a functional specialization of the dorsal part of the barreloids. After tracer injection in lamina 4 of the barrel cortex, they noticed that retrograde labeling occurred more commonly in the ventrolateral two-thirds of VPM, whereas injections in infragranular laminas produced many more labeled neurons in the dorsomedial portion of the barreloid, near Po. Subsequent studies also reported that the relay cells in the dorsalmost region of the barreloids form more elaborate dendritic trees and receive input from specific sets of PrV, reticular thalamic and corticothalamic fibers (Bourassa et al., 1995; Veinante and Deschênes, 1999; DésîletsRoy et al., 2002; Varga et al., 2002). The present study provides a 


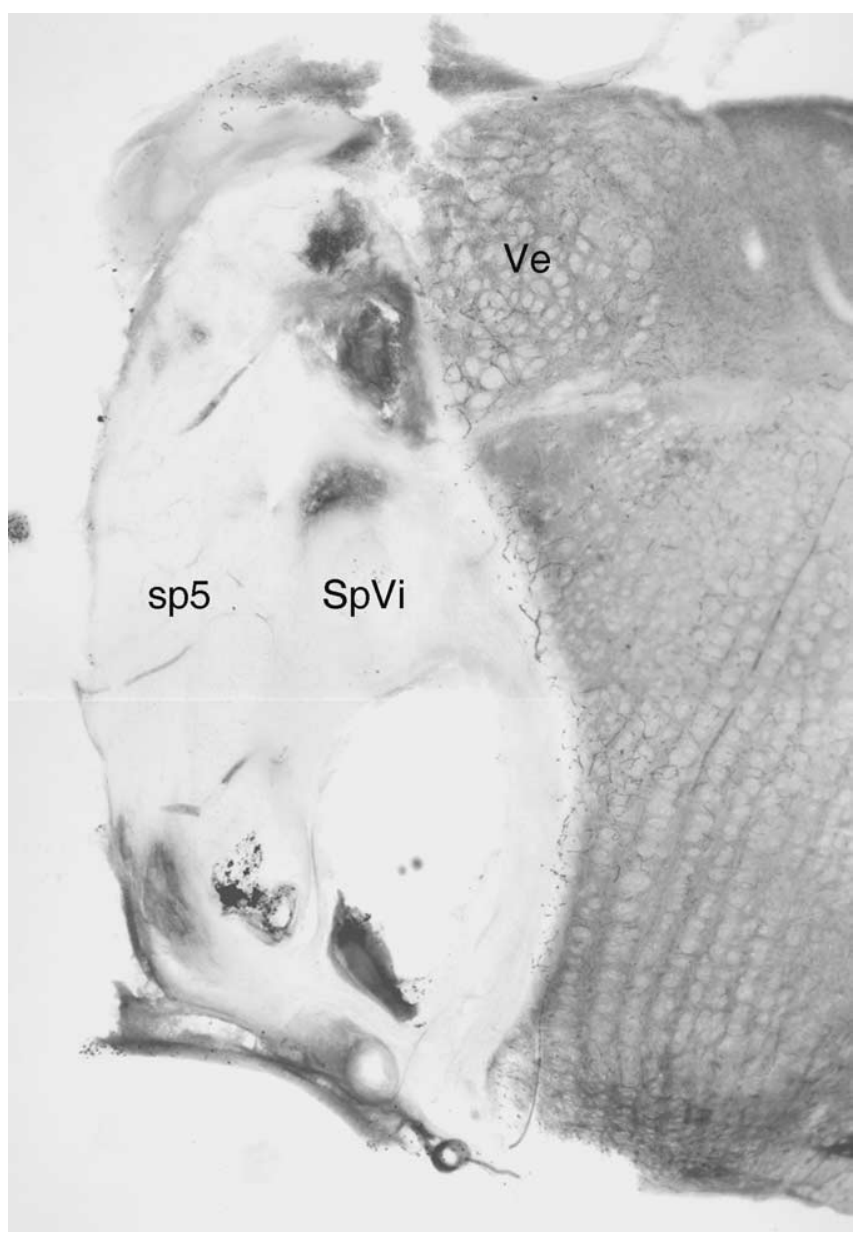

Figure 2. Frontal section through the brainstem (frontal plane $\sim 11.8 \mathrm{~mm}$ behind the bregma) showing the extent of an electrolytic lesion that destroyed the SpVi) and the spinal trigeminal tract (sp5). Ve, Spinal vestibular nucleus.

comprehensive explanation for these separate observations by showing that the relay cells in the head of barreloids form a parallel pathway of vibrissa information processing. This pathway differs from the classic lemniscal pathway, in that constituent thalamic cells have a multiwhisker receptive field and receive corticothalamic input from lamina 6 of the vibrissa motor cortex.

\section{Comparison with previous studies}

A number of previous studies have examined vibrissal responses in the VPM of the rat. They were performed under different types and regimens of anesthesia, and among those that paid attention to receptive field size, three provided electrode tract reconstructions that registered the location of the recorded units (Rhoades et al., 1987; Ito, 1988; Sugitani et al., 1990). Two of these studies reported that VPM neurons with large receptive fields were more numerous dorsally, whereas cells with a single whisker receptive field were recorded deeper in vertical electrode penetrations through VPM (Ito, 1988; Sugitani et al., 1990). Cells in VPMvl were apparently not sampled in these studies.

Although it has been well demonstrated that the receptive field size of VPM neurons depends on the depth of anesthesia (Friedberg et al., 1999; Aguilar and Castro-Alamancos, 2005), this dependence seems to apply primarily to the more numerous relay cells forming the core of the barreloids, because cells within the head and tail compartments maintained a large receptive field despite the deep level of anesthesia used in our experiments. One should also note that, because barreloids form curved, obliquely oriented rods with respect to the vertical, different ratios of mono-whisker and multiwhisker cells can be obtained, depending on the location of microelectrode descents and on the extent to which the entire thickness of the VPM is explored. In vertical electrode penetrations that explore the lateral aspect of the VPM (straddler and arcs 1-2 of whisker representation), multiwhisker cells in the head of the barreloids can be missed, or their number underestimated. Likewise, electrode tracts passing through the $\mathrm{E}$ and D barreloids in rostral VPM will miss VPMvl neurons because this region thins out rostrally. Together, these factors may explain why previous studies failed to recognize the unique properties of the cells in the head of the barreloids.

After cortical lesion, none of the cells recorded in Po responded to whisker deflection. This result accords with that of Diamond et al. (1992), who reported that cortical inactivation abolished vibrissal responses in Po. It should be noted, however, that cortical inactivation is not the primary cause of this lack of responsiveness. As recently demonstrated, cortical inactivation only suppresses long-latency responses $(\sim 15-20 \mathrm{~ms})$ that are mediated by cortical feedback in intact animals (Lavallée et al., 2005). Shorter-latency vibrissal responses ( $\sim 8 \mathrm{~ms})$, which persist after cortical lesion, only occur after lesion of the zona incerta, which exerts a strong feedforward inhibitory action in Po [Trageser and Keller, 2004; Lavallée et al. (2005), their Discussion].

\section{Input/output through the head of the barreloids}

Because relay cells in the head of the barreloids maintain strong vibrissal responses in SpVi-lesioned rats, their multiwhisker receptive field must arise from the PrV. This conclusion is consistent with our previous single-axon tracing study in which we reported that the dorsal part of the VPM receives input from two types of PrV cells: cells with a mono-whisker receptive field that form small clusters of terminals in a single barreloid and large multiwhisker-responsive cells that innervate Po and the dorsalmost sector of multiple barreloids (Veinante and Deschênes, 1999)

A previous study already demonstrated that cells in the tail of the barreloids project to S2 and to the dysgranular zone of S1 (Pierret et al., 2000). If cells in the head and core of the barreloids form separate pathways of vibrissal information, one would expect both populations of neurons to also differ in the way they innervate barrel cortex. Studies that examined the terminal arbors of single thalamocortical fibers in the barrel cortex reported terminal fields that consist of a dense plexus in layers 3-4 of a barrel column and of a sparse terminal field in the upper layer 6 of the same column (Jensen and Killackey, 1987; Pierret et al., 2000; Arnold et al., 2001). That later study also presented several examples of fibers that did not match this prototypical projection pattern, either by the spatial or laminar distribution of their terminal branches. Future labeling studies should reveal how this diversity relates to cell location in a barreloid, receptive field topography, and sensory response properties.

\section{Parallel pathways: functional implications}

If one defines a sensory pathway as a three-neuron chain that links a sensory organ to a specific area of the neocortex, then the vibrissal system of rodents comprises at least four parallel pathways of information processing: three pathways that relay information through the head, core, and tail of the barreloids, respectively, and another one through Po. Each of these pathways arises from a specific population of brainstem trigeminal neurons, transits through a different thalamic region, and, albeit not yet 

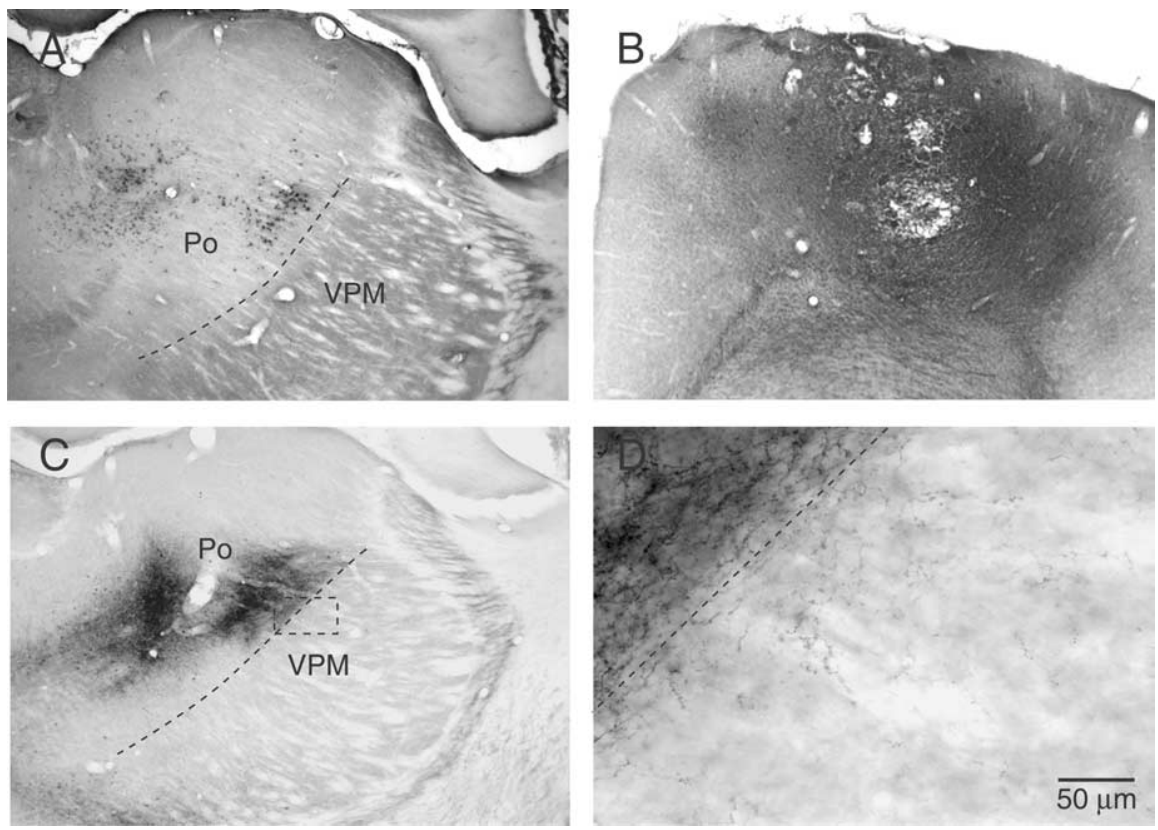

Figure 3. Motor cortex input to Po and dorsal VPM. $A$, After iontophoretic injection of FluoroGold in the deep layers of the motor area, retrograde labeling was found in Po and in the intralaminar nuclei, but no backlabeled cells were present in the VPM itself. $\boldsymbol{B}, \boldsymbol{C}$, Pressure injection of BDA in the deep layers of the motor area $(\boldsymbol{B})$ led to the anterograde labeling of a dense plexus of corticothalamic fibers in Po and intralaminar nuclei $(\boldsymbol{C})$. The boxed area in $\boldsymbol{C}$ is enlarged in $\boldsymbol{D}$, where one can see some axonal branches bearing boutons that invaded the dorsal VPM.

established for the "head pathway," has its own areal and laminar distribution in the neocortex. Moreover, for each of the relay stations in the thalamus, specific sets of corticothalamic and reticular thalamic projections have been demonstrated. Relay cells in the head of the barreloids, for instance, receive corticothalamic input not only from the motor cortex, but also from upper lamina 6 cells of $S 1$ that project to a single barreloid, and from lower lamina 6 cells that project to Po and across an arc of whisker representation in the head of the barreloids (Bourassa et al., 1995; Deschênes et al., 1998). By combining the retrograde labeling of a barreloid with the staining of single reticular thalamic cells activated by the corresponding vibrissa, some reticular axons were also observed to innervate exclusively the head of a barreloid (Désîlets-Roy et al., 2002).

Thus far, the respective functional role of the four parallel pathways remains ill defined. Because individual first-order afferents distribute terminals in each of the trigeminal nuclei (Hayashi, 1980; Henderson and Jacquin, 1995), second-order neurons receive the same sensory messages, which indicates that the parallel pathways do not relay inputs encoding different features of an object. They most likely convey information related to whisker motion (proprioception), texture and shape discrimination, and object location in the whisking space, or again different pathways may be operative in different behavioral contexts [e.g., the exploratory and object recognition modes discussed by Curtis and Kleinfeld (2006)]. Approximately $75 \%$ of the PrV cells have a receptive field dominated by a single vibrissa (Minnery and Simons, 2003), and their projections in the VPM show little convergence [on average, a VPM relay cell receives input from one to two PrV neurons (Castro-Alamancos, 2002; Deschênes et al., 2003)]. The prevailing view is that this fine-grained system serves texture and shape discrimination. The role of the other pathways remains as yet an open issue, but one can speculate that messages relayed through the head of the barreloids may somehow be re- lated to whisker motion, because this pathway can be directly modulated by corticothalamic messages from the motor cortex. It could be the pathway involved in relaying the fast signal encoding phase of whisker motion during free whisking (Fee et al., 1997; O'Connor et al., 2002; Crochet and Petersen, 2006). This possibility would be in line with recent evidence showing that during artificial whisking (one that is produced by facial nerve stimulation), some cells within the head and core of barreloids convey combined whisking and touch signals ( $\mathrm{Yu}$ et al., 2006).

\section{References}

Aguilar JR, Castro-Alamancos MA (2005) Spatiotemporal gating of sensory inputs in thalamus during quiescent and activated states. J Neurosci 25:10990-11002.

Arnold PB, Li CX, Waters RS (2001) Thalamocortical arbors extend beyond single cortical barrels: an in vivo intracellular tracing study in rat. Exp Brain Res 136:152-168.

Bourassa J, Pinault D, Deschênes M (1995) Corticothalamic projections from the cortical barrel field to the somatosensory thalamus in rats: a single-fibre study using biocytin as an anterograde tracer. Eur J Neurosci 7:19-30.

Castro-Alamancos MA (2002) Properties of primary sensory (lemniscal) synapses in the ventrobasal thalamus and the relay of high-frequency sensory inputs. J Neurophysiol 87:946-953

Castro-Alamancos MA, Calcagnotto ME (1999) Presynaptic long-term potentiation in corticothalamic synapses. J Neurosci 19:9090-9097.

Crochet S, Petersen CC (2006) Correlating whisker behavior with membrane potential in barrel cortex of awaked mice. Nat Neurosci 9:608-610.

Curtis JC, Kleinfeld D (2006) Seeing what the mouse sees with its vibrissae: a matter of behavioral state. Neuron 50:524-526.

Deschênes M, Hu B (1990) Electrophysiology and pharmacology of the corticothalamic input to lateral thalamic nuclei: an intracellular study in the cat. Eur J Neurosci 2:140-152.

Deschênes M, Veinante P, Zhang ZW (1998) The organization of corticothalamic projections: reciprocity versus parity. Brain Res Rev 28:286-308.

Deschênes M, Timofeeva E, Lavallée (2003) The relay of high-frequency signals in the whisker-to-barrel pathway. J Neurosci 23:6778-6787.

Désîlets-Roy B, Varga C, Lavallée P, Deschênes M (2002) Substrate for cross-talk inhibition between thalamic barreloids. J Neurosci 22: RC218(1-4).

Diamond ME, Armstrong-James M, Budway MJ, Ebner FF (1992) Somatic sensory responses in the rostral sector of the posterior group (POm) an in the ventral posterior medial nucleus (VPM) of the rat thalamus: dependence on the barrel field cortex. J Comp Neurol 319:66-84.

Fee MS, Mitra PP, Kleinfeld D (1997) Central versus peripheral determinants of patterned spike activity in rat vibrissa cortex during whisking. J Neurophysiol 78:1144-1149.

Friedberg MH, Lee SM, Ebner FF (1999) Modulation of receptive field properties of thalamic somatosensory neurons by the depth of anesthesia. J Neurophysiol 81:2243-2252.

Haidarliu S, Ahissar E (2001) Size gradients of barreloids in the rat thalamus. J Comp Neurol 429:372-387.

Hayashi H (1980) Distributions of vibrissae afferent fibers collaterals in the trigeminal nuclei as revealed by intra-axonal injection of horseradish peroxidase. Brain Res 183:442-446.

Henderson TA, Jacquin MF (1995) What makes subcortical barrels? In: Cerebral cortex, the barrel cortex of rodents, Vol 12 (Jones EG, Diamond IT, eds), pp 123-187. New York: Plenum.

Ito $M$ (1988) Response properties and topography of vibrissa-sensitive VPM neurons in the rat. J Neurophysiol 60:1181-1197. 
Jensen KF, Killackey HP (1987) Terminal arbors of axons projecting to the somatosensory cortex of the adult rat. I. The normal morphology of specific thalamocortical afferents. J Neurosci 7:3529-3543.

Land PW, Buffer SA, Yaskosky JD (1995) Barreloids in adult rat thalamus: three-dimensional architecture and relationship to somatosensory cortical barrels. J Comp Neurol 355:573-588.

Lavallée P, Deschênes M (2004) Dendroarchitecture and lateral inhibition in thalamic barreloids. J Neurosci 24:6098-6110.

Lavallée P, Urbain N, Dufresne C, Bokor H, Acsády L, Deschênes M (2005) Feedforward inhibitory control of sensory information in higher-order thalamic nuclei. J Neurosci 25:7489-7498.

McCormick DA, von Krosigk M (1992) Corticothalamic activation modulates thalamic firing through glutamate "metabotropic" receptors. Proc Natl Acad Sci USA 89:2774-2778.

Minnery BS, Simons DJ (2003) Response properties of whisker-associated trigeminothalamic neurons in rat nucleus principalis. J Neurophysiol $89: 40-56$.

O'Connor SM, Berg RW, Kleinfeld D (2002) Coherent electrical activity between vibrissa sensory areas of cerebellum and neocortex is enhanced during free whisking. J Neurophysiol 87:2137-2148.

Paxinos G, Watson C (1986) The rat brain in stereotaxic coordinates. San Diego: Academic.

Pierret T, Lavallée P, Deschênes M (2000) Parallel streams for the relay of vibrissal information through thalamic barreloids. J Neurosci 20:7455-7462.

Pinault D (1996) A novel single-cell staining procedure performed in vivo under electrophysiological control: morpho-functional features of juxtacellularly labeled thalamic cells and other central neurons with biocytin or Neurobiotin. J Neurosci Methods 65:113-136.

Rhoades RW, Belford GR, Killackey HP (1987) Receptive-field properties of rat ventral posterior medial neurons before and after selective kainic acid lesions of the trigeminal brain stem complex. J Neurophysiol 57:1577-1600.

Sugitani M, Yano J, Sugai T, Ooyama H (1990) Somatotopic organization and columnar structure of vibrissae representation in the rat ventrobasal complex. Exp Brain Res 81:346-352.

Trageser JC, Keller A (2004) Reducing the uncertainty: gating of peripheral inputs by zona incerta. J Neurosci 24:8911-8915.

Varga C, Sik A, Lavallée P, Deschênes M (2002) Dendroarchitecture of relay cells in thalamic barreloids: a substrate for cross-whisker modulation. J Neurosci 22:6186-6194.

Veinante P, Deschênes M (1999) Single- and multi-whisker channels in the ascending projections from the principal trigeminal nucleus in the rat. J Neurosci 19:5085-5095.

Veinante P, Jacquin M, Deschênes M (2000) Thalamic projections from the whisker-sensitive regions of the spinal trigeminal complex in the rat. J Comp Neurol 420:233-240.

Williams MN, Zahm DS, Jacquin MF (1994) Differential foci and synaptic organization of the principal and spinal trigeminal projections to the thalamus in the rat. Eur J Neurosci 6:429-453.

Yu C, Derdikman D, Haidarliu S, Ahissar E (2006) Parallel thalamic pathways for whisking and touch signals in the rat. PloS Biol 4:819-825. 